Journal of Nepal Geological Society, 2019, vol. 58 (Sp. Issue), pp. 153-162

DOI: https://doi.org/10.3126/jngs.v58i0.24600

\title{
An approach of preparing earthquake induced landslide hazard map: a case study of Nuwakot District, central Nepal
}

\author{
*Harish Dangi, Tara Nidhi Bhattarai, and Prem Bahadur Thapa \\ Department of Geology, Tri-Chandra Campus, Tribhuvan University, Kathmandu, Nepal \\ *Corresponding author: harishhappy27@gmail.com
}

\begin{abstract}
TThe Gorkha Earthquake-2015 triggered landslides which are widespread in central Nepal. The landslides swept away physical infrastructures like roads, schools, public and residential buildings, and cultivated lands at several locations. This indicated that the decision makers were not aware of the fact that the locations for possible earthquake-induced landslides can be predicted, and physical infrastructure development can be planned accordingly. What is needed for the purpose is an earthquake-induced landslide hazard map which is a useful tool in decision making, particularly for finding safer geographical locations for residential and public building construction, and also for other physical infrastructure development. Immediately after the Gorkha Earthquake-2015, JICA prepared an earthquake-induced landslide hazard map of the Gorkha and the Sindhupalchowak Districts using a certain methodology. But there remains a research question regarding whether the same methodology can be applied in preparing earthquake-induced landslide hazard maps of other earthquake-affected districts located away from the epicenter area. The main purpose of this research was to apply the JICA methodology to prepare an earthquake-induced landslide hazard map of the Nuwakot District, central Nepal which is the one if the most affected district by Gorkha earthquake 2015. The second purpose was to examine whether the map captured the ground reality or not. While preparing the input data required, four major disaster factors were taken into consideration which includes, among others, slope inclination, slope direction, relationship with the major thrust and distance from the epicenter. These factors were classified and characterized according to their nature and condition. The result was then analyzed by using quantification theory. An earthquake-induced landslide hazard map was then prepared using QGIS as a major software tool. The map was also verified through ground-truthing visiting several locations of the study site. The proposed methodology can be used to prepare similar maps in other affected districts of Gorkha earthquake 2015, and suitable sites for constructing physical infrastructures like roads, residential and public buildings can also be identified using the maps.
\end{abstract}

Keywords: Hazard map, QGIS, JICA methodology, Quantification theory II, Nuwakot District

Paper Received: 15 Jan 2019

Paper Accepted: 20 Mar 2019

\section{INTRODUCTION}

The Nepal Himalaya is tectonically divided into four longitudinal units having different stratigraphic and evolutionary characters from south to north i.e. Siwaliks, Lesser Himalaya, Higher Himalaya and Tibetan Tethys Himalaya (Gansser 1964). Large scale intra-continental thrusts such as Himalayan Frontal Thrust (HFT), Main Boundary Thrust (MBT) and Main Central Thrust (MCT) (Gansser 1964) separates these tectonic units. Due to the broken, weathered, rocky and uneven mountain topography and insubstantial geology, the young Himalayan Mountains and hills are subjected to frequent instability. Frequent earthquakes, high-intensity rainfall with weak geology and diverse topography straightly contribute to several types of landslides.

The occurrence of a disaster is a result of contact between social activities and a natural phenomenon of unusual scale. A serious impact may occur due to the natural disaster on society and economy. Disaster prevention is one of the most needed but sensible and challenging issues in the present context of Nepal. Nepal is very prone to landslide due to the various distinctive factors such as climatic, topographic and several geological complexities. The widespread landslide has caused serious casualties and property loss and resulted in a great threat to post-earthquake reconstruction. It is almost impossible to avoid or remove natural phenomenon responsible for landslide but they can be classified according to their respective nature and role in the disaster field. It is essential to identify, evaluate and delineate landslide hazard-prone areas for proper strategic planning and mitigation (Pan et al., 2008; Anbalagan, 1992; Bisson et al., 2014; Raghuvanshi et al., 2014; Girma et al., 2015). A landslide hazard map can be an important tool for the prevention of natural disaster-induced by the landslide. Landslide generally depends upon extrinsic factor and intrinsic factor. The intrinsic factor includes geological factors (lithology or soil type, structural discontinuity characteristic, groundwater condition, slope aspect, slope angle, etc. whereas the extrinsic factor include seismicity (Keefer, 2000; Parise and Jibson, 2000; 


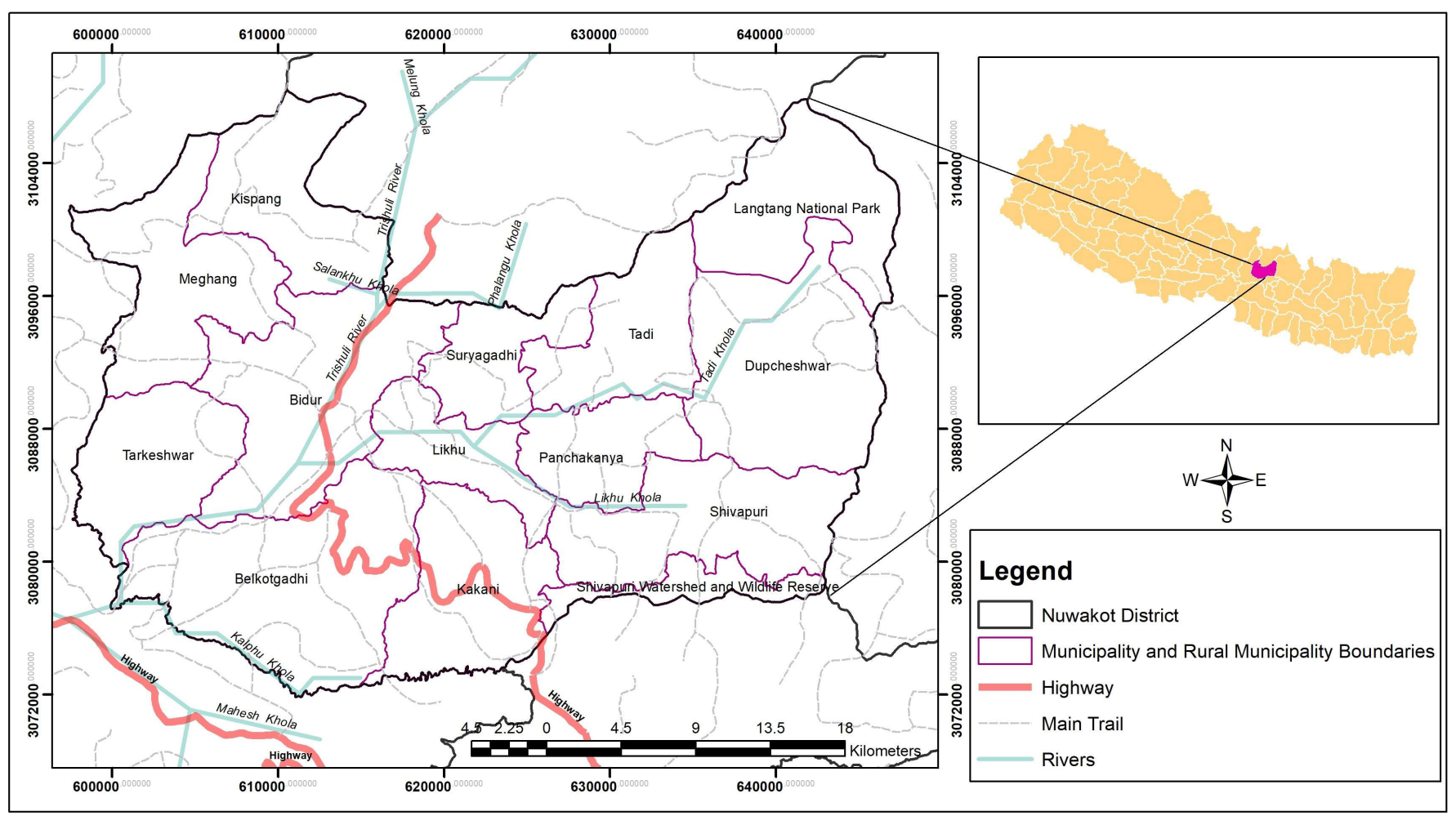

Fig. 1: Nuwakot District boundary (Study area)

Bommer and Rodriguez, 2002), rainfall (Collison et al., 2000; Dai and Lee,2001; Dahal et al., 2006) and manmade activities such as; construction activities and cultivation practices in mountainous regions (Raghuvanshi et al., 2014).

Here, this research is related to earthquake-induced landslide hazard mapping so, distance from the thrust and past epicenter distribution are taken as major extrinsic factors. These factors can be classified according to their nature. A certain procedure is needed with a certain theory to formulate the obtained values.

Immediately after the Gorkha Earthquake-2015, JICA project team for recovery and rehabilitation program prepared an earthquake-induced landslide hazard map of the Gorkha and the Sindhupalchowak Districts. But there remains a research question regarding whether the same methodology can be applied in preparing earthquake-induced landslide hazard maps of other earthquake-affected districts located away from the epicenter area. The main purpose of this research was to apply the JICA methodology to prepare an earthquake-induced landslide hazard map of the Nuwakot District, central Nepal which is the one if the most affected district by Gorkha earthquake 2015 and evaluate the result.

\section{STUDY AREA}

Geologically, the area lies in the Lesser Himalayan and Higher Himalayan Zones of central Nepal. It is surrounded by the Rasuwa, the Dhading, the Kathmandu and the Sindhupalchok Districts. The area has a very distinct feature of geology. It consists of two Municipalities and ten rural Municipalities covering the area of 1,121 square kilometers as shown in fig 1. It has the total population of 277,471 (CBS, 2011) with the population density of $253.2 / \mathrm{km}^{2}$.

The study area constitutes a hilly terrain exhibiting rugged topography with a diversity of landforms, which is characterized by the elevated mountains and the deep river valleys. The area shows the ridge, spur, and saddle and valley morphology generally with the moderate to steep slope with dense drainage network. It consists of geography with the lowest elevation of approximately 518 meters and highest elevation of 4873 meters from the sea level.

\section{METHODOLOGY}

First required data such as DEM, Geological Map, epicenter data were collected. Software required during whole procedure are QGIS, Adobe-Photoshop, Microsoft Excel, Python, etc. Field study was done to validate the Digitized polygon of landslide. A systematic step by step procedure as shown in Fig. 2 was followed during the preparation of the hazard map which is adopted from the JICA project team for recovery and rehabilitation after Gorkha earthquake 2015.

\section{Data collection and analysis}

\section{Evaluation of factors with landslide distribution}

Two intrinsic factors ((i) slope aspect and (ii) slope angle) and two extrinsic factors ((iii) distance from the thrust and (iv) 


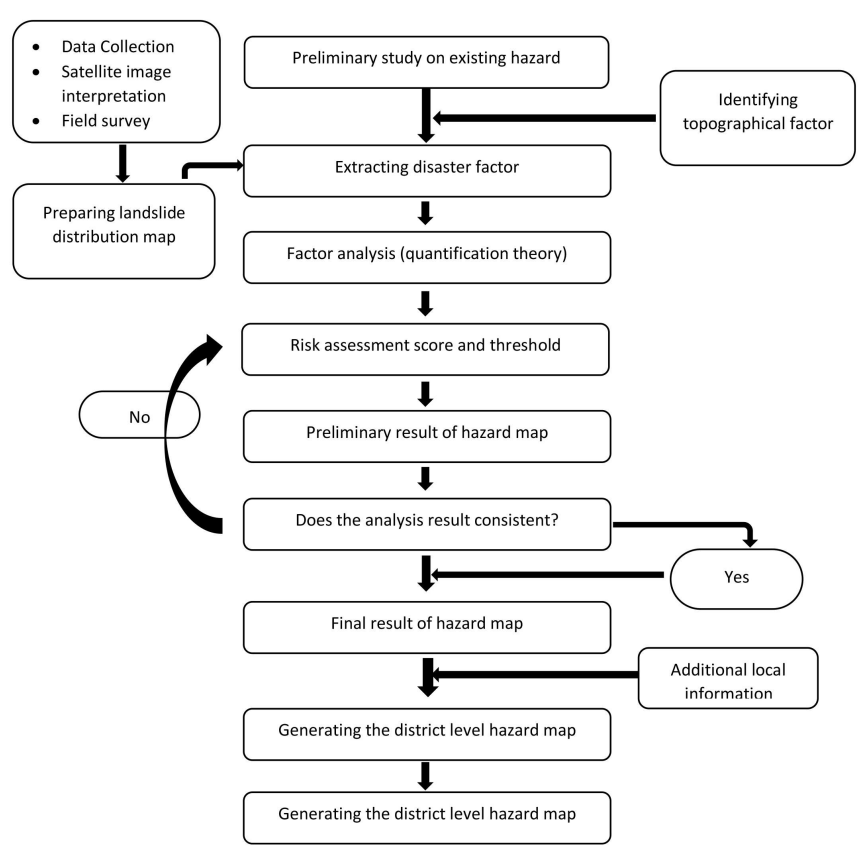

Fig. 2: Step by step methodology

distance from epicenter) were considered for the preparation of earthquake-induced landslide hazard map. The secondary judgment to give weightage to the factors is done on the basis of the result obtained by the analysis of these factors and landslide distribution. Following workflow (Fig. 3) presents general steps in sequence:
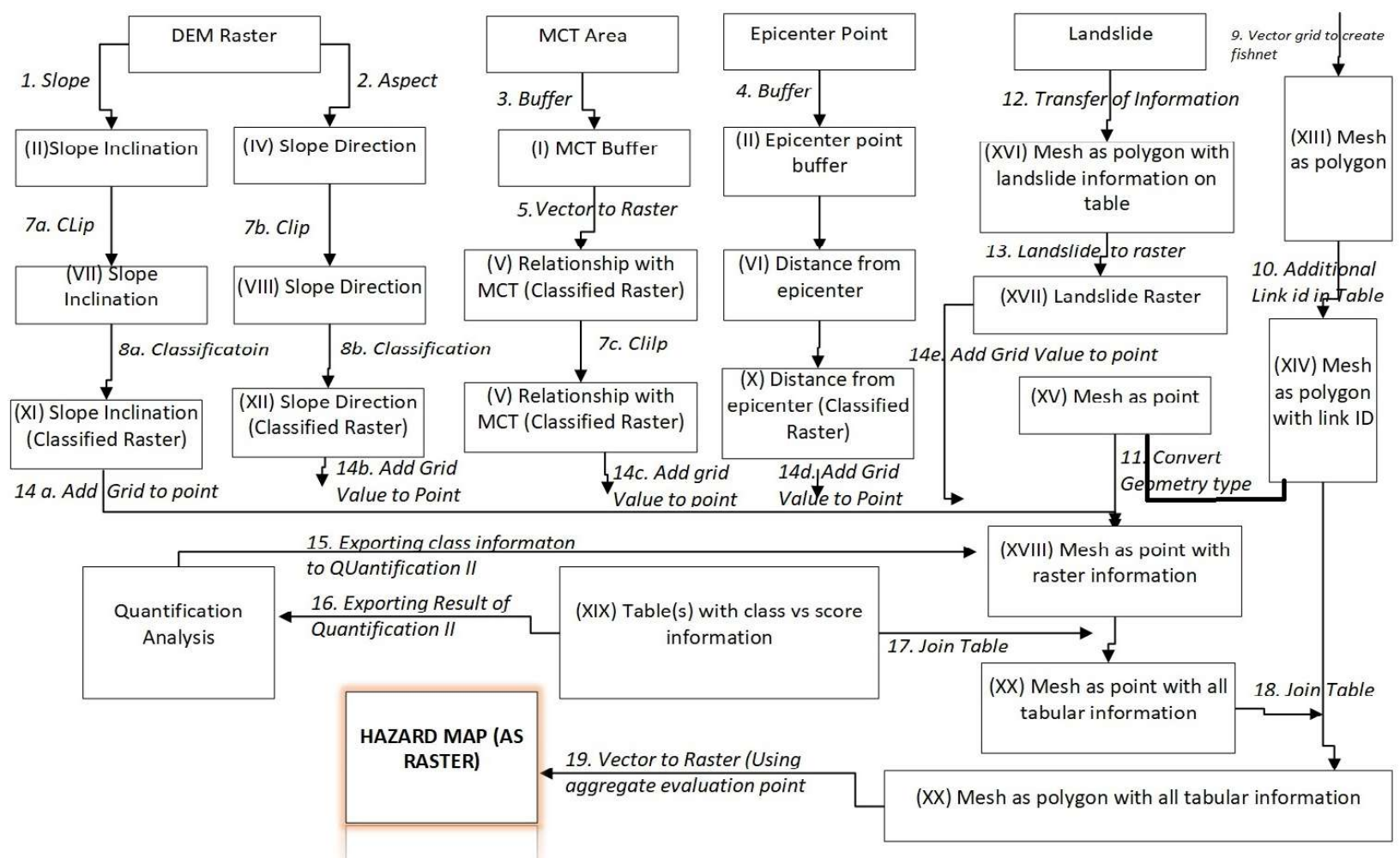

Fig. 3: Work flow during the map preparation

\section{Landslide inventory}

With the help of historical imagery option in google earth, co-seismic landslides were distinguished and digitized which we can see in Fig 4 as an example. To distinguish the co-seismic landslides, image from google earth before earthquake (Before 25th April) and after earthquake (2015/5/24) was used. Either the seismic effect triggered landslide or reactivated the landslide, both types of landslides were taken into consideration. All the co-seismic landslides were digitized in Google Earth Pro. After digitizing all the earthquake induced landslides, verification was done by ground truthing (Fig. 5), and landslide inventory map was prepared (Fig. 6).

\section{Slope angle}

The slope is one of the major intrinsic factors to induce landslide. The steeper slope, the chance of instability is higher. The gravity pull which is the main driving force for instability is directly proportional to the slope gradient (Raghuvanshi et al., 2014). Here the Nuwakot District comprised of a higher slope variation. After extracting the slope of the Nuwakot District from DEM, it was classified and characterized (Table 1). Using landslide inventory (Fig. 6) and slope angle distribution (Fig. 7), in which the slope angle was extracted from individual $27 \mathrm{~m} \times 27 \mathrm{~m}$ pixels, the majority of landslides shared 20 to 50 degrees of slope (Table 2).
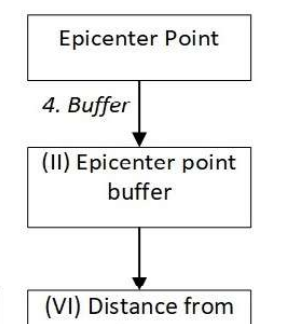
epicenter
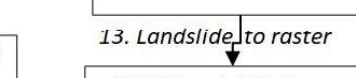

12. Transfer of Information

(XVI) Mesh as polygon with landslide information on table
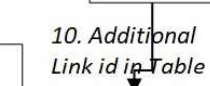

10. Additional ink id in table as polygon ith link ID 

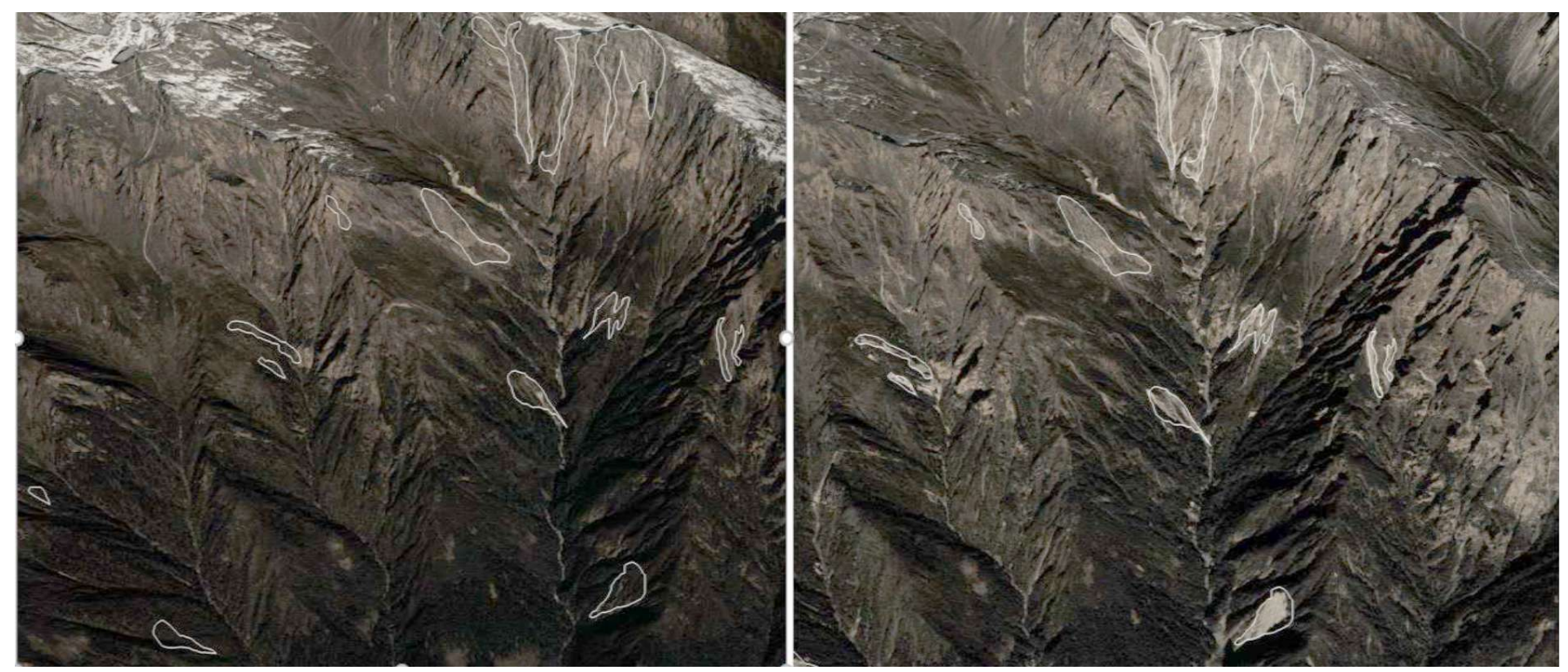

Fig. 4: Landslide distribution before and after Gorkha earthquake
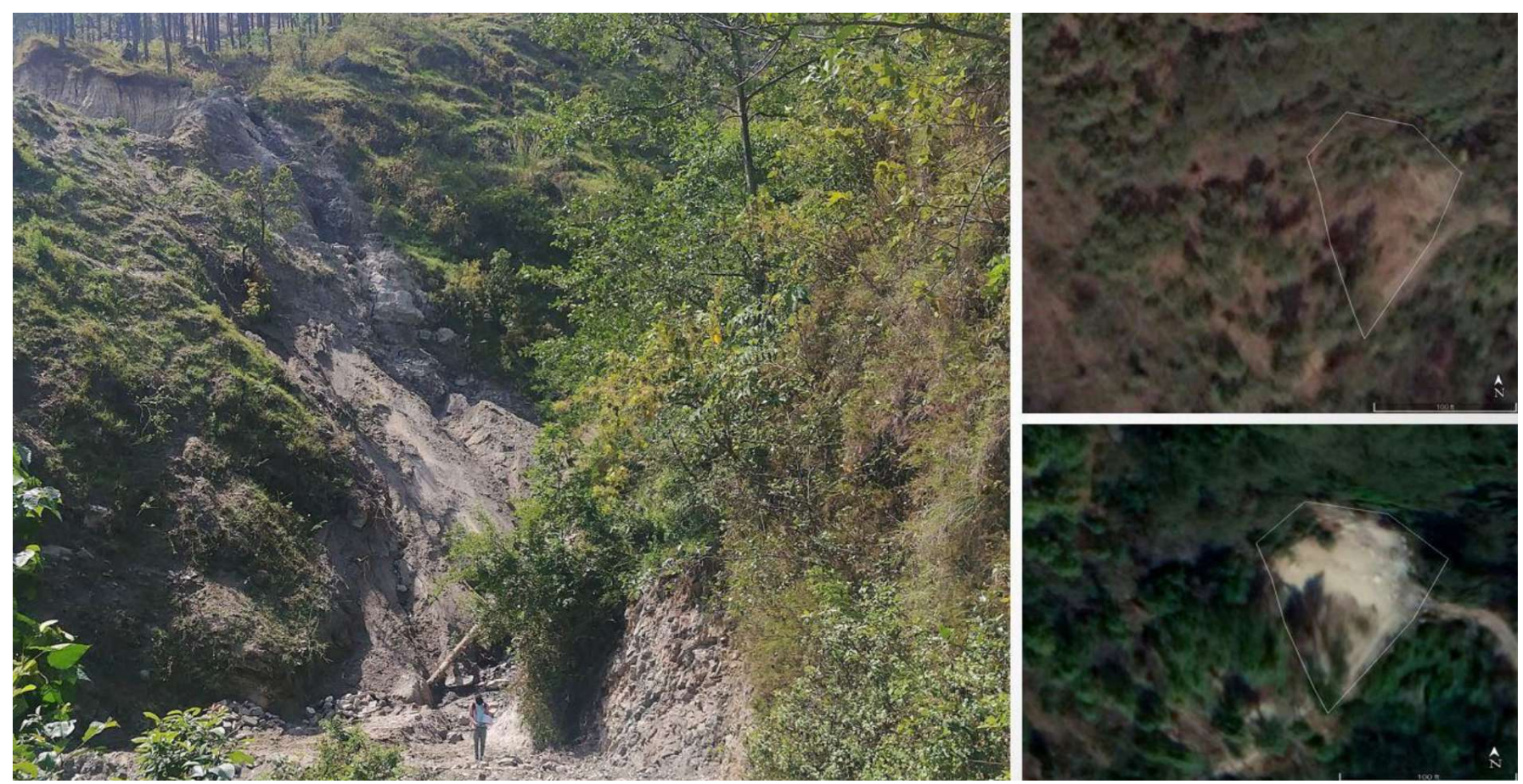

Fig. 5: Ground truthing of earthquake induced landslides: (a) shows the actual ground reality, (b) the landform before Gorkha earthquake and (c) the ground condition after Gorkha earthquake.

\section{Slope aspect}

After extracting slope aspect from DEM, it was classified and characterized (Table 1). Analysis of the aspect classification (Table 1) from aspect distribution map (Fig. 8) and landslide distribution revealed that a higher percentage of landslide were distributed on the slope inclined toward south direction whereas lower percentage with slope inclined toward the northwest (Table 2).

\section{Distance from the thrust}

Major thrust passing through the Nuwakot District is the Main Central Thrust (MCT). It was extracted by georeferencing and digitizing a geological map of Nepal downloaded from the geological society of Japan. It was buffered with $10 \mathrm{~km}$ distance toward both directions east and west (Fig. 9). Later on, it was characterized and classified as shown in the Table 1. Analysis of thrust relationship and landslide distribution reveals that the 


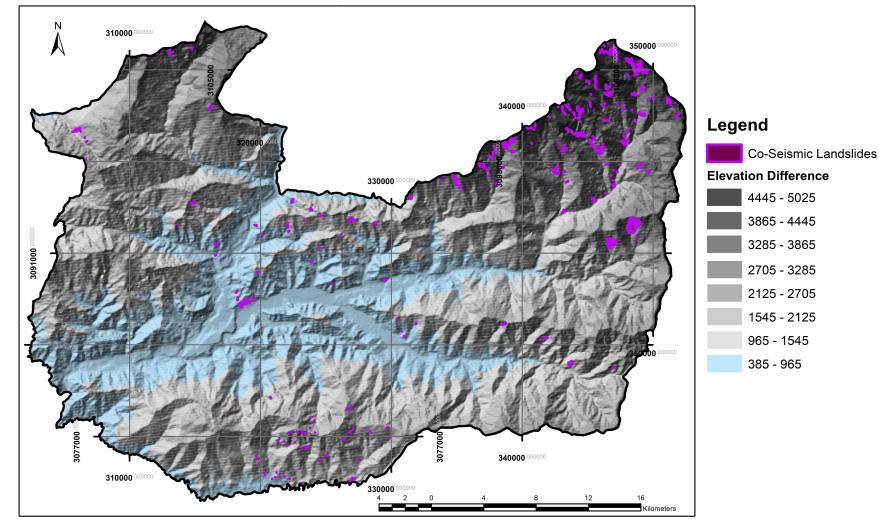

Fig. 6: Landslide inventory

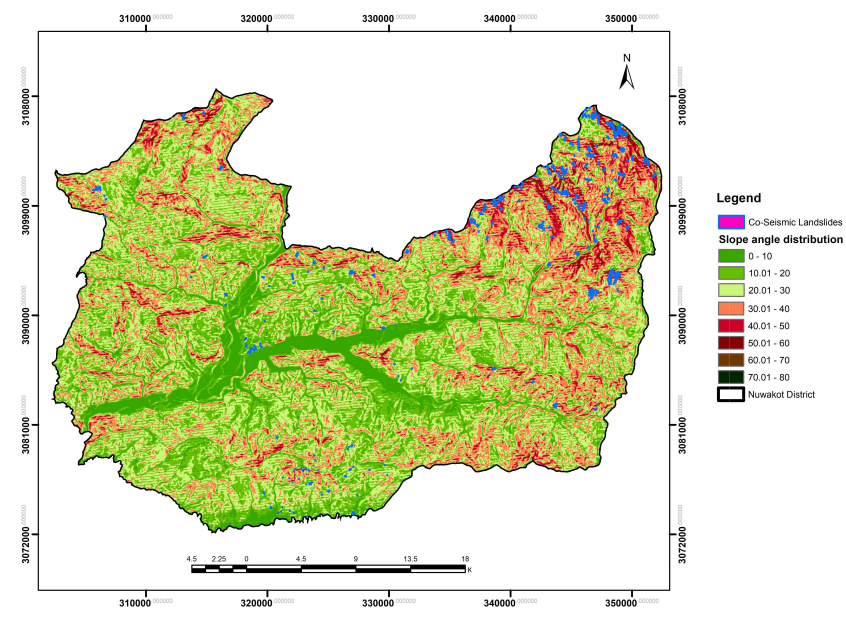

Fig. 7: Slope angle distribution map

higher concentration of landslide is found at the distance ranging from 10-20 KM from the MCT (Table 2), whereas lower concentration of landside is found to be along the MCT.

\section{Distance from epicenter}

Data of all existing earthquakes was taken from the website of Nepal Seismological Centre, in which, date, UTC

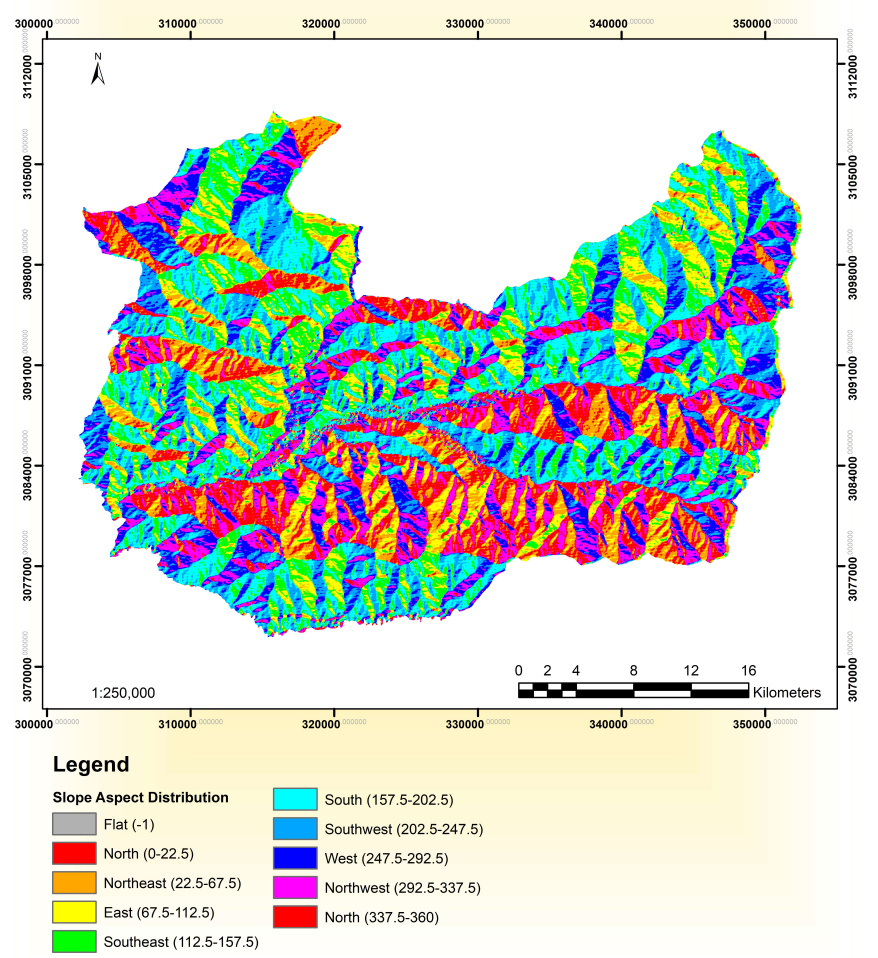

Fig. 8: Slope aspect distribution map

time, Latitude/Longitude, Magnitude (ML) and Epicentre are listed. Later on, epicenter data were imported to QGIS, merged and buffered with the distance of $10 \mathrm{~km}, 20 \mathrm{~km}, 30 \mathrm{~km}$ and 40 $\mathrm{km}$ as shown in Fig. 14. The characterization and classification of distance from epicenter are shown in the Table 3 . The analysis of merged buffered epicenter and landslide distribution showed that $96 \%$ of landslides are inside the buffered distance of 10 $\mathrm{km}$ and rest on the buffered distance of 10-20 km (Table 2).

\section{Evaluation by quantification theory II}

\section{Quantification theory II}

Quantification theory II is a discriminant analysis method when the data is given by the qualitative data.

Table 1: Category and classification of the slope angle distribution, slope aspect distribution and distance from the MCT

\begin{tabular}{llll}
\hline Category & $\begin{array}{l}\text { Slope angle distribution } \\
\text { Classification }\end{array}$ & $\begin{array}{l}\text { Slope aspect distribution } \\
\text { Classification }\end{array}$ & $\begin{array}{l}\text { Distance from the MCT } \\
\text { Classification }\end{array}$ \\
\hline 1 & $0-10$ & North & Inside MCT \\
2 & $10.01-20$ & North East & East $0-10 \mathrm{~km}$ under \\
3 & $20.01-30$ & East & East $10-20 \mathrm{~km}$ under \\
4 & $30.01-40$ & South East & East $20-30 \mathrm{~km}$ under \\
5 & $40.01-50$ & South & East $30 \mathrm{~km}$ or more \\
6 & $50.01-60$ & South West & West $0-10 \mathrm{~km}$ under \\
7 & $60.01-70$ & West & West $10-20 \mathrm{~km}$ under \\
8 & $70.01-80$ & North West & West 20-30 km under \\
\hline
\end{tabular}


Table 2: Relation of percent landslide distribution with slope angle, slope aspect and proximity to the MCT

\begin{tabular}{lll}
\hline & Categories & \% Landslides \\
\hline Slope angle & $0-10$ & 1.70 \\
& $10-20$ & 8.52 \\
& $20-50$ & 81.01 \\
& $50-60$ & 7.46 \\
Slope aspect & $60-70$ & 0.21 \\
& North & 9.13 \\
& North East & 7.88 \\
& East & 5.66 \\
& South East & 16.26 \\
& South & 30.11 \\
& South West & 26.41 \\
& West & 4.15 \\
& North West & 0.37 \\
MCT distance & Along the MCT & 5.57 \\
& $0-10 \mathrm{~km}$ & 37.85 \\
& $10-20 \mathrm{~km}$ & 53.57 \\
& $0-10 \mathrm{~km}$ below & 4 \\
& $10-20 \mathrm{~km}$ below & 96 \\
\hline
\end{tabular}

The discriminant analysis uses quantitative variables as explanatory variables, whereas Quantification II uses qualitative data, categorical data as a characteristic variable.

- Qualitative data: divided incline, divided direction

- Categorical data: North of MCT or Inner of MCT

In this theory, these variables called explanatory variables. By using this method and comparing important factors, we can find the main affecting factors of the targeted phenomena. The main calculation routine is based on Excel VBA (Visual Basic for Applications) published by Mr. Shigeo Aoki, professor of social informatics at Gunma University. This calculation routine computation is terminated when the cumulative contribution rate exceeds $80 \%$.

\section{Calculation content of the quantification II}

By calculating the general eigenvalue case we can get the eigenvector for the maximum eigenvalue. The eigenvalue obtained equals the correlation ratio.

When the discrimination between groups based on the maximum eigenvalue is not sufficient, eigenvectors are obtained by using the second largest eigenvalue (correlation ratio). Likewise, theoretically, eigenvalues of the explanatory variable number -1 are obtained, but the computation is terminated when the cumulative contribution rate exceeds $80 \%$.

For the most part, if the first eigenvalue and the second eigenvalue ( 1 axis and 2 axis) do not yield a cumulative correlation ratio of 0.8 or more, it would be preferable to review

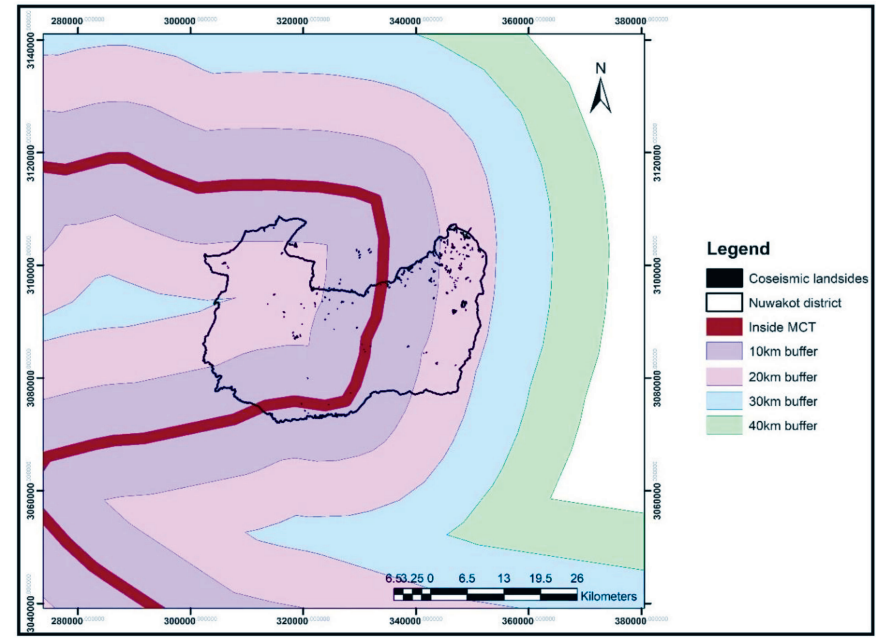

Fig. 9: Thrust (MCT) proximity map

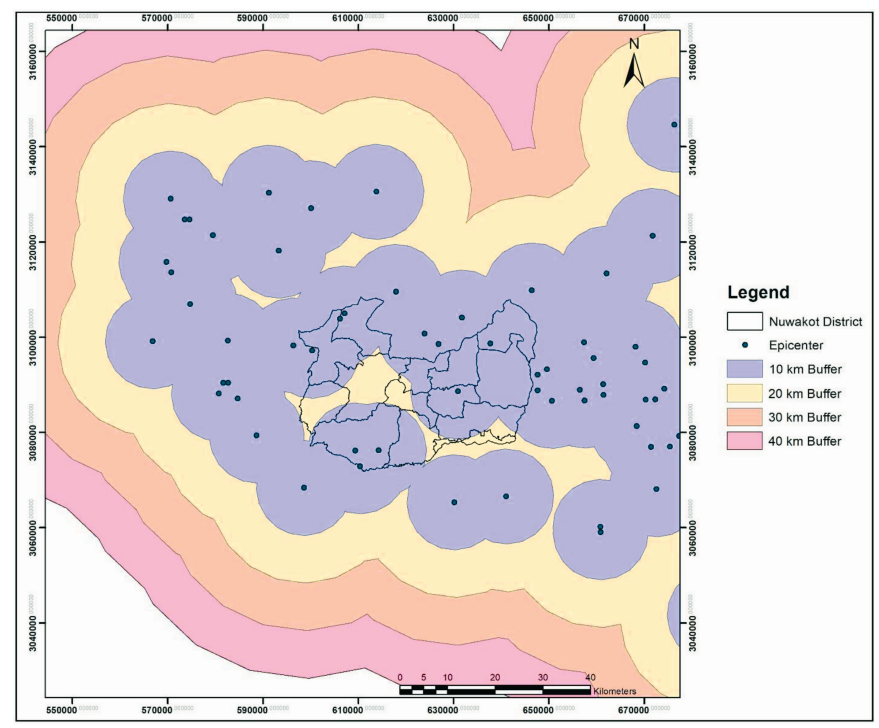

Fig. 10: Epicenter proximity map

the composition of explanatory variables.

\section{Evaluation of the data}

The primary evaluation to give the weight to the category was obtained from the quantification theory. After extracting the data from the attribute table (Table 4), the data was analyzed in excel sheet using quantification II.

Table 3: Category and classification of epicenter buffer

\begin{tabular}{ll}
\hline Epicenter distance, Classification & Category \\
\hline $0-10 \mathrm{~km}$ below & 1 \\
$10-20 \mathrm{~km}$ below & 2 \\
$20-30 \mathrm{~km}$ below & 3 \\
$30 \mathrm{~km}$ and more & 4 \\
\hline
\end{tabular}


Table 4: Certain part of attribute table of point shape file including all factors

\begin{tabular}{lllllll}
\hline ID & Link ID & $\begin{array}{l}\text { Landslide } \\
\text { classification }\end{array}$ & $\begin{array}{l}\text { Slope } \\
\text { classification }\end{array}$ & $\begin{array}{l}\text { Aspect } \\
\text { classification }\end{array}$ & $\begin{array}{l}\text { MCT } \\
\text { classification }\end{array}$ & $\begin{array}{l}\text { Epicenter } \\
\text { classification }\end{array}$ \\
\hline 0 & 1 & 0.00000000000 & 3 & 6 & 5 & 1.00000000000 \\
1 & 2 & 0.00000000000 & 3 & 6 & 5 & 1.00000000000 \\
2 & 3 & 0.00000000000 & 3 & 6 & 5 & 1.00000000000 \\
3 & 4 & 0.00000000000 & 3 & 6 & 5 & 1.00000000000 \\
4 & 5 & 0.00000000000 & 3 & 6 & 5 & 1.00000000000 \\
5 & 6 & 0.00000000000 & 3 & 6 & 5 & 1.00000000000 \\
6 & 7 & 0.00000000000 & 3 & 6 & 5 & 1.00000000000 \\
7 & 8 & 0.00000000000 & 3 & 6 & 5 & 1.00000000000 \\
8 & 9 & 0.00000000000 & 3 & 6 & 5 & 1.00000000000 \\
\hline
\end{tabular}

\section{Primary and secondary evaluation}

As all the data are imported from the attribute table in the form of excel data. The extracted data were imported in excel where the theory is programmed.

After running the program in excel we get the primary evaluation data or first evaluation data. The expert judgment is needed to make it more practical. By researching all the factors used in hazard map and landslide inventory which is explained already, the second evaluation was done as shown in Table 5. After the final evaluation, each category of the items gets a certain value as shown in above table. All the category score of similar pixels is added to get a single final value of respective pixel. Now after addition, the vector polygon data is converted into raster form with the consideration of the final added value of all category score.

\section{Color representation}

Every individual square pixel has four coordinates with $27 * 27 \mathrm{~m}$ area and each such spatial area will consist the addition of the secondary evaluation value of slope aspect, slope angle, distance from thrust and distance from epicenter. So, in general every factor has a common spatial area and the addition of secondary evaluation point is done for every common pixel and then they are distinguished by user defined color which is explained in Table 8. Here, the color represents the hazard condition. Based on field situation and logical consideration the Map is generalized into four hazardous zones which are Low hazard, Medium hazard, High Hazard and Very High Hazard as shown in Table 6. Here Hazard zone represents the hazard level of any area compared to other level of hazard of another area.

\section{RESULT AND DISCUSSION}

As shown in Fig. 11, the prepared map consists of four hazard zones (low, medium, high and very high). The lowhazard zone consists of $52.13 \%$ of total pixel covering the area of 584.37 sq. Km.
Similarly, medium hazard zone consists of $33.15 \%$ of total pixel covering the area of $371.61 \mathrm{sq}$. km. The high-hazard zone consists of $11.65 \%$ of the total pixel covering the area of 130.59 sq. $\mathrm{km}$. The very high-hazard zone consists of $3.16 \%$ of the total pixel with the area of 35.42 square kilometers.

The major source of extraction of intrinsic factors for the preparation of the map is 27 m DEM which is not high-

Table 5: Result after using quantification theory in excel

\begin{tabular}{|c|c|c|c|c|}
\hline Factors & Range & Categories & $\begin{array}{c}\text { 1st } \\
\text { Evaluation }\end{array}$ & $\begin{array}{c}\text { 2nd } \\
\text { Evaluation }\end{array}$ \\
\hline \multirow{8}{*}{$\begin{array}{l}\text { Incline } \\
\text { (degree) }\end{array}$} & $0 \sim 10$ & 1 & 1 & 0 \\
\hline & $10 \sim 20$ & 2 & 1 & 1 \\
\hline & $20 \sim 30$ & 3 & 2 & 2 \\
\hline & $30 \sim 40$ & 4 & 11 & 11 \\
\hline & $40 \sim 50$ & 5 & 7 & 7 \\
\hline & $50 \sim 60$ & 6 & 6 & 3 \\
\hline & $60 \sim 70$ & 7 & 3 & 2 \\
\hline & $70 \sim 80$ & 8 & 0 & 0 \\
\hline \multirow[t]{9}{*}{ Direction } & Flat & -1 & 3 & 0 \\
\hline & $\mathrm{N}$ & 1 & 4 & 2 \\
\hline & $\mathrm{NE}$ & 2 & 2 & 1 \\
\hline & $\mathrm{E}$ & 3 & 4 & 2 \\
\hline & SE & 4 & 7 & 4 \\
\hline & $\mathrm{S}$ & 5 & 10 & 6 \\
\hline & SW & 6 & 5 & 3 \\
\hline & W & 7 & 1 & 2 \\
\hline & NW & 8 & 1 & 1 \\
\hline \multirow[t]{6}{*}{ MCT } & E $0-10 \mathrm{~km}$ & 1 & 5 & 3 \\
\hline & E $10-20 \mathrm{~km}$ & 2 & 4 & 2 \\
\hline & E $20-30 \mathrm{~km}$ & 3 & 2 & 1 \\
\hline & W 0-10 km & 5 & 15 & 3 \\
\hline & $\mathrm{W} 10-20 \mathrm{~km}$ & 6 & 3 & 2 \\
\hline & W 20-30 km & 7 & 1 & 1 \\
\hline \multirow[t]{3}{*}{ Epicenter } & $0-10 \mathrm{~km}$ & 1 & 3 & 3 \\
\hline & $10-20 \mathrm{~km}$ & 2 & 2 & 2 \\
\hline & $20-30 \mathrm{~km}$ & 3 & 1 & 1 \\
\hline
\end{tabular}


Table 6: Color representation and total points

\begin{tabular}{lc}
\hline Range of colors & Total points \\
\hline Blue & $0 \sim 11$ \\
Low risk & \\
Yellow & $12 \sim 16$ \\
Medium risk & \\
Red & $17 \sim 23$ \\
High risk & \\
Dark Maroon & $24 \sim 25$ \\
\hline
\end{tabular}

resolution data. Every pixel of the map is $27 \mathrm{~m}$ in length and breadth which means, there will be a single result within whole $27 \mathrm{~m} \times 27 \mathrm{~m}$ area although the area may include several ranges of hazard if high resolution data is used. Here the first evaluation is done using Quantification theory II whereas second evaluation i.e. expert judgment is done in the basis of relationship between the landslide factors and co-seismic landslide inventory, it does not include the evaluation on the basis of other factor conditions. There are several other landslide factors which could be included during the map preparation but as it is regional map, it was quite impossible. Such as, geology is one of the important factors which plays an important role in landslide, but to do detail geological investigation which include rock testing, soil testing, kinematic analysis, subsurface water level testing, etc. along the whole area takes lots of time and effort and money. This map includes the factors which are responsible and which trigger other factors for the slope failure.

There is always an involvement of various factors during slope failure. The role of the factors varies from one to another, so during the preparation of the hazard map scoring the category of the factors also differ from one to other depending upon the role for the slope failure. Most landslides are concentrated on the steep slopes $>35$ of $\mathrm{V}$ shape inner gorges, bounded by convex slopes along the Trishuli River (Tsou et al., 2018). Shaking may be amplified in the convex part of $\mathrm{v}$ shaped inner Gorge, terrace scarps and creast slopes (Keefer, 1984; Wakai and Ugai, 2004). The steep George of gneiss and sandstone or quartzite are loosening by gravitational force (Tsou et al. 2017). From this also we can conclude that topography situation has a lot to do with landslide activation.

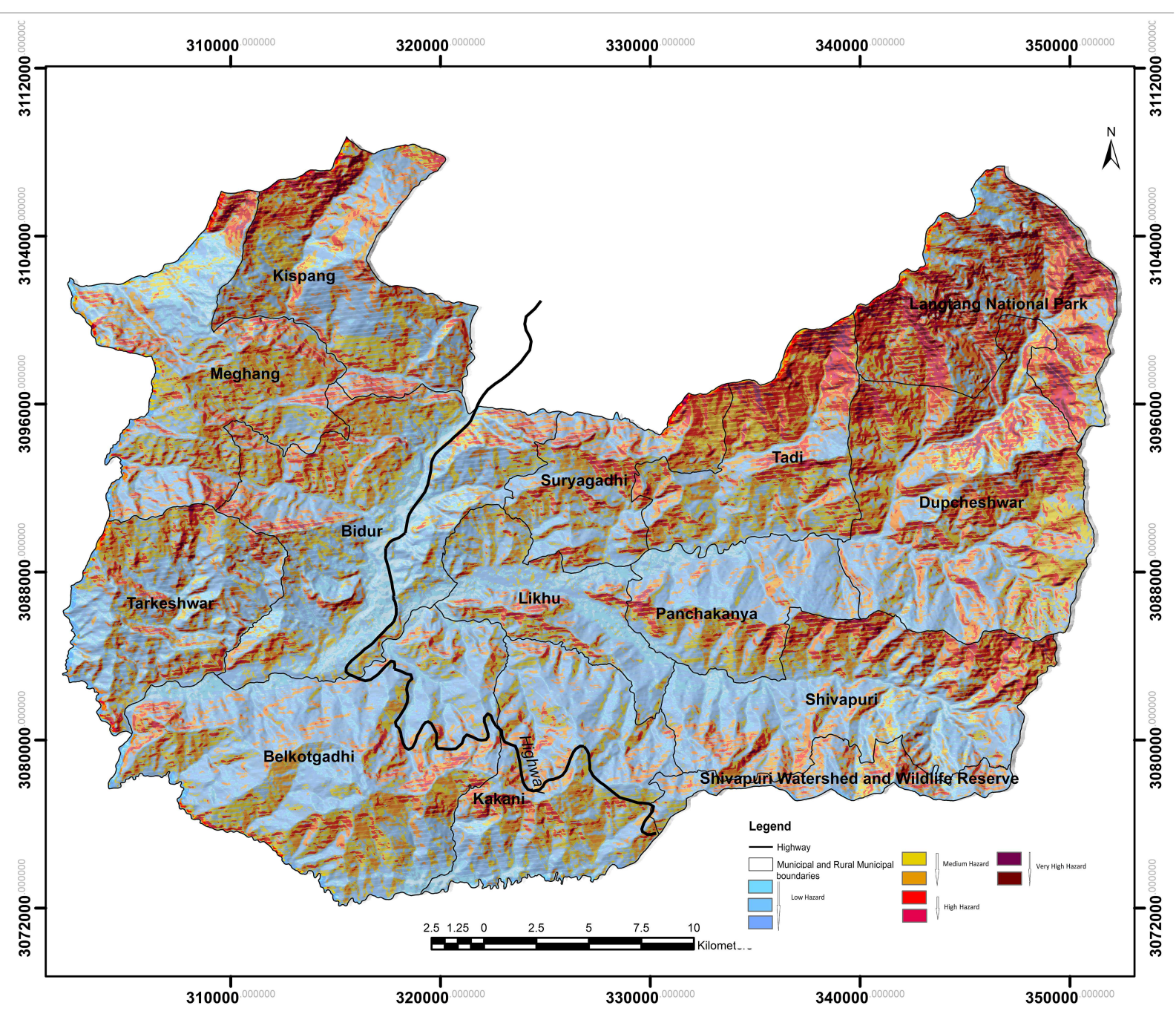

Fig. 11: Earthquake induced landslide hazard map of the Nuwakot District 
Here, the higher score is given to slope category as it is a primary factor where gravity pull affects the slope condition and continuously pulls the slope surface down and the Nuwakot District has very high topography variation, to find huge piece of flat land is almost impossible. The maximum landslides that occurred were in the slope ranging from 30 to 50 degrees. Here there are two reason behind it. First is the maximum distribution percentage of slope angle of the Nuwakot District which increases the probability of including the landslide in this range and second is the weathering grade. Most of the slope in this range are result of weathering, Weathering weakens the slope stability and as other factors contribute at the same place, there is high probable of slope failure. The aspect has another important role in slope failure in different ways. As the aspect can categories high moisture area where sunlight hits less and dry area where sunlight hits the most. The dip direction of the majority rock can also be defined by aspect as the same formation of the rock majorly tends to deep on the same direction, although in this case field investigation is an important part. As described in result the southern part of the Nuwakot District covers the maximum surface area and consist of around $90 \%$ of co-seismic landslide. Regionally, this aspect is more prone to landslide and definitely gets higher score among all the aspect category. It concludes that the higher changes of landslides are in this aspect part. The MCT is another factor which definitely have a certain role in slope instability. In future initiation of earthquake may have direct relationship with the MCT and rock closure to it are weaker in which if other factors gives affect then there are chances of slope failure although the area closer to the MCT may not have high hazard zone as the hazard map depends upon other factors also. In the case of epicenter, area close to epicenter has maximum chances of slope failure and origin of crack is another result which later on after long time, it may trigger landslide. The concept of merged epicenter is to accept that the next earthquake will happen close to or inside that area. Indeed, there is higher chances of earthquake to happen in the similar area as the reason of earthquake around that area is same in maximum cases. There is certain region where energy gets saved and release at once in future resulting the earthquake.

After the earthquake, several landslides are triggered later on. Not only landslide other various natural process gets deflected with certain change in topography and geology. As Tomita et al. (2018) discussed about the post effect of earthquake, there is total $1.3 * 10000000$-meter cube debris masses are considered to be hidden and ready to move sooner or later. This event will affect highly to human directly or indirectly. Two hydropower projects, the Mailung Khola Hydropower Project and the Trishuli 3A Hydropower Project headwork will have direct affect as they are downstream to the river. Here still several landslides are occurring day by day increasing the number of casualties and property loss. It is for sure that the next earthquake will again bring numbers of co-seismic landslides. Preparation of earthquake induced landslide hazard map can be an important tool to cope this natural disaster in well-mannered way.
To validate the landslide hazard map, overlay analysis along with field verification was done.

The prepared map was than digitized again and converted into 4 distinct KML files representing four different mode of hazards i.e. low, medium, high and very high which helped distinguishing the hazard zones in field. Validation showed that $81 \%$ of past landslide fall in high hazard zone and $9 \%$ of past landslide fall in very high hazard zone. Here remaining $10 \%$ of past landslide falls in low and medium hazard zone. The reason behind this has a lot to do with the use of limited causative factors. Other factor such as PGA, land use, Rock orientation, etc. has also a role of contribution to such landslides. Here, the prepared map has delineated the potential area for landslide and can distinguish the place in term of landslide hazard.

\section{CONCLUSIONS}

The study was done in the Nuwakot District (one of the most affected districts in term of earthquake-induced landslide disaster), central part of Nepal. The goal of the study was to check the certain methodology already applied to the Gorkha and the Sindhupalchok, Districts. As it is a regional level of mapping, four major causative factors were taken which are; slope angle, slope aspect, distance from merged epicenter and distance from the major thrust. Here, 27 meter in length and breadth pixel were created and were given value to each pixel with the help of quantification theory II and expert judgment. Expert judgement was done on the basis of the spatial relationship between the prepared causative factor map and past earthquakeinduced landslide history.

By checking out the pixel values and distinguishing them in term of hazards, the low-hazard zone consists of $52.13 \%$ of total pixel covering the area of 584.37 square kilometers. Similarly, medium hazard zone consists of $33.15 \%$ of total pixel covering the area of 371.61 square kilometers. The high-hazard zone consists of $11.65 \%$ of the total pixel covering the area of 130.59 square kilometers. The very high-hazard zone consists of $3.16 \%$ of the total pixel with the area of 35.42 square kilometers. The finding revealed that after an earthquake, topography including rock orientation, soil property, slope angle, slope aspect has a great role to induce the landslide. It revealed that the Main Central Thrust (MCT) has not a significant role to contribute to earthquake-induced landslide whereas epicenter distance is directly proportional to landslide occurrence. The closer the topography to epicenter, chances of slope failure are higher. Majority landslides shared 20 to 50 degree of slope angle and $81 \%$ of landslide were found in this slope surface.

During validation, with the help of past landslide data, this overlay analysis resulted that $81 \%$ of the landslide falls under high-hazard zone $8 \%$ of the total landslides falls under very high-hazard zone So, in total $89 \%$ of earthquake-induced landslide falls on the high and very high-hazard zone.

As the produced map is of the regional level type so it can be used to make a general concept for various activities in 
the regional level of planning. For the local level of planning other causative factors should be added which can vary from place to place.

\section{ACKNOWLEDGEMENTS}

The authors are thankful to the Department of Geology, Tri-Chandra Multiple Campus for providing field equipment and necessary facilities from the department. We are also grateful to the professors, lecturers and staffs for their suggestions, encouragement and support. We offer special thanks to Pushkar Bhandary for field support throughout the study. We are indebted to local people from studied area, Nuwakot for their kindness and information provided during the field work.

\section{REFERENCES}

Anbalagan, R., 1992, Landslide hazard evaluation and zonation mapping in mountainous terrain. Eng. Geol. v. 32, pp. 269-277. https://doi.org/10.1016/0013-7952(92)90053-2

Bisson, M., Spinetti, C. and Sulpizio, R., 2014, Volcaniclastic flow hazard zonation in the sub-apennine vesuvian area using GIS and Remote Sensing. Geosphere 10.

https://doi.org/10.1130/GES01041.1

Bommer, J.J., Rodriguez, C.E., 2002, Earthquake-induced landslide in Central America. Eng. Geol. v. 63, 189p.

https://doi.org/10.1016/S0013-7952(01)00081-3

Collison, A., Wade, S., Griffiths, J., Dehn, M., 2000, Modelling the impact predicted climate change on landslide frequency and magnitude in SE England. Eng. Geol. v. 55, pp. 205218. https://doi.org/10.1016/S0013-7952(99)00121-0

Dahal, R.K., Hasegawa, S., Masuda, T., Yamanaka, M., 2006, Roadside slope failure in Nepal during torrential rainfall and their mitigation. Disaster Mitigation of Debris Flows, Slope Failures and Landslides, pp. 503-514.

Dai, F.C., Lee, C.F., 2001, Terrain-based mapping of landslide susceptibility using a geographical information system: a case study. Can. Geotech. J. v. 38, pp. 911-923.

https://doi.org/10.1139/t01-021

Gansser, A., 1964, Geology of the Himalayas. Wiley Interscience, London. 289p.

Girma, F., Raghuvanshi, T.K., Ayenew, T., Hailemariam, T., 2015, Landslide hazard zonation in Ada Berga District, Central Ethiopia- a GIS based statistical approach. J. Geomatics 90, pp. 25-38.

CBS, 2011. Household and population by districts, Central Bureau of Statistics (CBS) Nepal, 2011.

Keefer, D.K., 1984, Landslides caused by earthquakes.
Geological Society of America bulletin, v. 95, pp.406-421. h t t p s : / / d o i.org/10.1130/00016 7606(1984)95<406:LCBE>2.0.CO;2

Keefer, D.V., 2000, Statistical analysis of an earthquake-induced landslide distribution -the 1989 Loma Prieta, California event. Eng. Geol. v. 58, pp. 231-249.

https://doi.org/10.1016/S0013-7952(00)00037-5

Pan, X., Nakamura, H., Nozaki, T., Huang, X., 2008, A GISbased landslide hazard assessment by multivariate analysis Landslides. J. Jpn. Landslide Soc. v. 45(3), 187-195.

https://doi.org/10.3313/jls.45.187

Parise, M., Jibson, R.W., 2000, A seismic landslide susceptibility rating of geologic units based on analysis of characteristics of landslides triggered by the 17 January, 1994 Northridge, California earthquake. Eng. Geol. v. 58, pp. 251-270.

https://doi.org/10.1016/S0013-7952(00)00038-7

Raghuvanshi, T.K., Ibrahim, J. and Ayelew, D., 2014, Slope stability susceptibility evaluation parameter (SSEP) rating scheme- an approach for landslide hazard zonation. Jour. Afr. Earth Sci. 99, pp. 595-612.

https://doi.org/10.1016/j.jafrearsci.2014.05.004

Tomita, H., Nakata, A.M., Konagai, K., Matsushima, T., Shiga, M., Ikeda, T., Pokhrel, R.M., 2018, Landslides triggered by the 2015 Gorkha Earthquake and analysis of their longlasting impact. Journal of Nepal Geological Society, v. 55 (Sp. Issue), pp.77-84.

https://doi.org/10.3126/jngs.v55i1.22793

Tsou, C.Y., Chigira, M., Higaki, D., Sato, G., Yagi, H., Sato, H.P., Wakai, A., Dangol, V., Amatya, S. C., and Yatagai, A., 2017, Topographic and geologic controls on landslides induced by the 2015 Gorkha earthquake and its aftershocks: an example from the Trishuli Valley, central Nepal, Landslides. https://doi.org/10.1007/s10346-017-0913-9

Tsou, C.Y., Higaki, D., Chigira, M., Yagi, H., Dangol, V., Amatya, S.C., Hayashi, K., Kato, H., 2018, Topographic characteristic of landslide induced by 2015 Gorkha earthquake,Nepal. Journal of Nepal Geological Society, v. 55 (Sp. Issue), pp.69-75.

https://doi.org/10.3126/jngs.v55i1.22792

Wakai, A. and Ugai, K., 2004, A simple constitutive model for the seismic analysis of slopes and its applications. Soils and Foundations, v. 44, pp. 83-97.

https://doi.org/10.3208/sandf.44.4_8 